\title{
A review of the reasons for high prevalence and rapid progression of COVID-19 in men
}

\author{
Neda Taghizabet $^{1}$, Fatemeh Rezaei-Tazangi ${ }^{{ }^{*} \oplus}$, Hossein Roghani-Shahraki $^{3^{\circledR}}$ \\ 'Department of Anatomical Sciences, School of Medicine, Shiraz University of Medical Sciences, Shiraz, Iran \\ ${ }^{2}$ Department of Anatomical Sciences, Faculty of Medicine, Fasa University of Medical Sciences, Fasa, Iran \\ ${ }^{3}$ Student Research Committee, Shiraz University of Medical Sciences, Shiraz, Iran
}

\section{Correspondence to:}

Fatemeh Rezaei-Tazangi, Email:

f.rezaei67@yahoo.com, f.rezaei@

fums.ac.ir

Received: 21 July 2021

Accepted: 14 Oct. 2021

ePublished: 25 Oct. 2021

Keywords: COVID-19, Gender difference, Blood pressure, Immune system

\begin{abstract}
Previous studies have demonstrated a relationship between gender and COVID-19 outcomes. In addition, this is confirmed that men have more danger of progressing an acute type of the illness than women, specifies the significance of miscellaneous data related to male and female patients with COVID-19. In other words, some factors like hormonal levels and immune function may interact with each other. A perception of the fundamental reasons for gender diversities in COVID-19 patients can beget a chance for disease prevention and faster treatment. The present study evaluates the role of gender in the incidence and progression of the COVID-19 disease. It has been explained that how gender affects angiotensin-converting enzyme 2 (ACE2), which is a basic factor for the COVID-19 pathogenesis introducing the sex diversities in platelet function, immune reactions and how sex hormones affect immune functions, also the effect of androgens on transmembrane protein serine protease 2 (TMPRSS2) receptor in COVID-19 patients was investigated.
\end{abstract}

Citation: Taghizabet N, Rezaei-Tazangi F, Roghani-Shahraki H. A review of the reasons for high prevalence and rapid progression of COVID-19 in men. J Prev Epidemiol. 2022; 7(1):e03. doi: 10.34172/jpe.2022.03

\section{Introduction}

In December 2019 and January 2020, the new coronavirus, which causes acute respiratory syndrome, spread from Wuhan, China, around the world and is now a serious threat to public health. The SARSCoV-2 virus, one type of coronavirus, has caused the COVID-19 epidemic $(1,2)$. Data obtained from all over the world and the United States and elsewhere consider that the disease is more aggressive in men than women. Reviewing past studies can reveal the molecular mechanisms, interactions and how the disease progresses faster in men. Despite the almost equal prevalence of the disease in men and women, clinical findings show that the disease progresses faster in men and has more symptoms. Gender, regardless of age and underlying disease, can significantly affect disease progression and death. Complications and mortality are higher in men $(3,4)$. Therefore, this study principally aimed to examine the impact of sex differences on the symptoms and mortality caused by COVID-19 disease.

\section{Objectives}

According to recent clinical studies, among patients hospitalized for COVID-19 disease, the progression and mortality of the disease

\section{Key point}

The male patients with COVID-19 are at a higher risk of developing the intense case of this disease in comparison with female patients. Among COVID-19 patients men have a higher risk of developing the severe form of the disease compared to women. Furthermore, the mortality rate due to the disease in men is higher than women; therefore, more attention is required for evaluation of sex as an important variable.

is higher than in men. In this study, an attempt is made to investigate the causes of these differences.

\section{Material and Methods \\ Search method and databases}

Content English and Persian articles related to the effect of gender on the prevalence and progression of Covid-19 were reviewed. Comprehensive researches were performed on Iranian and international databases, containing Iran Medex, ProQuest, PubMed, Scopus, Google Scholar, and Scientific Information Database. Every associated article comprised the following keywords; sex hormones, gender difference, COVID-19, blood pressure, immune system and platelets. Besides, to find valuable provenance the referral list of each extracted article was assessed.

Copyright $\odot 2022$ The Author(s); Published by Society of Diabetic Nephropathy Prevention. This is an open-access article distributed under the terms of the Creative Commons Attribution License (http://creativecommons.org/licenses/by/4.0), which permits unrestricted use, distribution, and reproduction in any medium, provided the original work is properly cited. 


\section{Choice indexes}

At first, the papers were chosen through vetting titles and abstracts. Those papers which met the desired criteria were analyzed. The criteria $(a)$ papers had been indexed in one of the aforesaid databases; $(b)$ articles in Persian or English; (c) articles had some keywords that have been mentioned in the research method in the titles. The excluded papers were those that repeated in more than one database, and also non-original articles like epistles to the editor and short communication.

\section{Data extraction}

Each article was exactly studied and assessed, then the data were collected and written into special sheets containing the author name, publication date, sampling, processing approach and results. Next, the articles were analysed qualitatively. After a precise assessment of the titles, abstracts, and cited manuscripts, finally, 45 articles were selected following the desired criteria.

\section{Results}

\section{Sex hormones and blood pressure}

Previous studies suggested that sex hormones can create gender difference in blood pressure. Sex steroid hormones such as androgens and estrogens had a significant effect on the regulation of blood pressure (5). Men had a higher danger of cardiovascular disease (CVD) in comparison with postmenopausal women of the same age. Testosterone has a prominent effect on the evolution and preservation of cardiac hypertrophy, vascular dysfunction, and hypertension induced by angiotensin II (Ang II). At physiologically pertinent concentrations, testosterone caused the expansion of the Ang II- induced hypertension with correlated enhance in the AT1R/AT2R ratio (AT: angiotensin receptor) and contraction of mesenteric arteries to phenylephrine and Ang II; (1) the ratio of body weight and the expression of atrial natriuretic peptide mRNA in the left ventricle; and (2) myocardium fibrosis. Attendance of testosterone caused cardiac hypertrophy, vascular dysfunction, and hypertension induced by Ang II. The virus of SARS-CoV-2 links to the ACE2 through spike protein (S). Furthermore, TMPRSS2 is needed for the virus to enter the cell.

Similarly, the SARS-CoV-1 virus which created the SARS pandemic in 2003, links to ACE2. ACE2 is a homologue of angiotensin-converting enzyme 1 (ACE1), a piece of the renin-angiotensin system (RAS), and a dipeptidyl carboxypeptidase. Angiotensinogen secreted to angiotensin I by the liver are cleaved by renin product of the juxtaglomerular cells in the kidney. The ACE1 cleaves angiotensin I to angiotensin II. Angiotensin II links to the receptors of angiotensin type 1 (AT1) and angiotensin type 2 (AT2). The linking between Angiotensin II and AT1 causes increased blood pressure, pro-inflammatory and pro coagulation events, aldosterone production with sodium and water retention, and vasoconstriction.
Heart failure and acute respiratory distress syndrome (ARDS) are the negative outcomes of angiotensin II. AT1 blockers are broadly utilized as anti-hypertension agents and have useful influences in the protection of the brain and other body organs. The ACE2 interacts with ACE1 and angiotensin II. Angiotensin II and angiotensin I are directly cleaved to angiotensin by ACE2. Angiotensin has anti-inflammatory influences by linking to the Mas receptor and also causes vasodilatation. The destructive effects of ACE1/angiotensin II/AT1 axis are counterregulated by useful cardioprotective and neuroprotective effects, caused by activation of ACE2/Ang/Mas axis (Figure 1). In rodents that have suffered a stroke, angiotensin has anti-inflammatory and neuroprotective effects. The ACE2 is expressed in various human tissues such as endothelial/smooth muscle cells in the brain, the small intestine, and lungs. Moreover, in the neurons of mice, ACE2 is expressed. The ischemic stroke is prevented by overexpression of ACE2 in the endothelial progenitor or neuronal cells. SARS-CoV-1 and 2 viruses evacuate ACE2 via endocytosis of the receptor after entering to cell, exiting ACE1 without counteracting with angiotensin II production. Angiotensin II increases lung damage and too endothelial function in the brain, heart, and several other organs. The ACE2 decreases in the lung with ageing, that this reduction is greater in males compared to females. Simultaneously, the activity of ACE1-angiotensin II system enhances by ageing. This can justify the high death rate due to COVID-19 disease in the senescent and men (6-8).

\section{Effect of androgens on TMPRSS2 receptor}

The SARS-CoV2 can enter the cell through two ACE2 receptors and also cellular serine protease (TMPRSS2) $(9,10)$. TMPRSS2 is involved in several viral infections, such as middle east respiratory syndrome (MERS), SARS, the current COVID-19, and also some influenza infections. It is an important factor in viral infection. The TMPRSS2 gene is expressed in numerous cells including the kidney, liver, pancreas, small intestine, adult colon, lung, and mainly in the adult prostate. It is located on the human chromosome 21q.22.3, encoding a 492 amino acid polypeptide with five distinct domains; a serine protein domain, a receptor domain, a cytoplasmic domain, a transmembrane domain, and a low-density lipoprotein domain. Androgen receptor is essential for transcription of the TMPRSS2 gene because it has not been yet illustrated that there is another regulatory factor of the TMPRSS2 promoter in humans (11).

Since androgen therapy increases the activation of zymogen TMPRSS2 in cell culture, it shows that androgens regulate TMPRSS2 at the level of transcription and translation (12).

Androgen receptor activation leads to transcription of TMPRSS2 $(13,14)$. Hormone therapy therefore increases the amount of TMPRSS2 that the virus uses to enter the cell. When the TMPRSS2 protein is blocked by its 


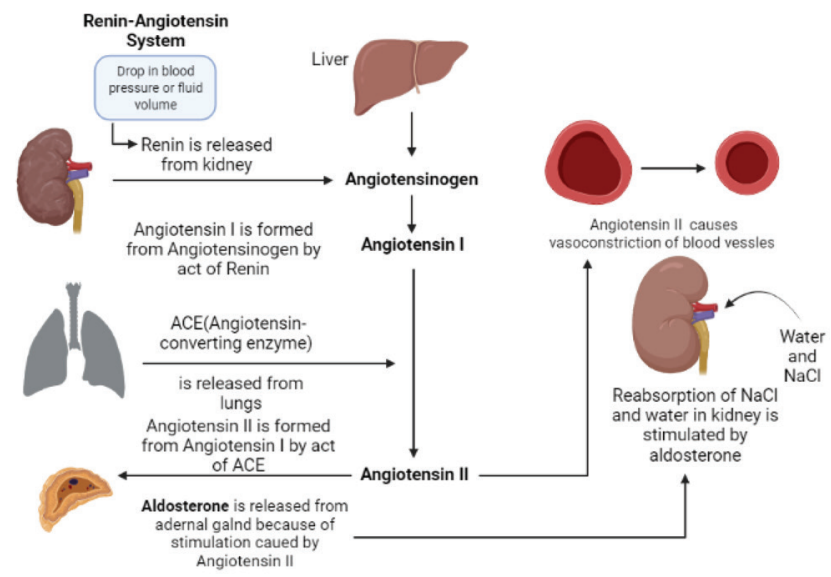

Figure 1. Regulation of blood pressure by the renin-angiotensin-aldosterone system in humans

blocking drugs, the virus cannot enter the host cell. This offers a promising way to treat this infection (Figure 2) (15). In addition, there are currently approved drugs such as bromhexine syrup that act to inhibit the proteolytic activity of this enzyme (16-18). Using bromhexine, a clinically proven serine proteinase inhibitor that can prevent cells from getting infected with the SARS-CoV virus and human coronavirus NL63 (HCoV-NL63), thus inhibiting TMPRSS2 in human lung cells by bromhexine SARS-CoV-2 infection is significantly reduced (19-23).

\section{Sex hormones effects on immune system}

Sex hormones have a significant effect on all cells of the body, including immune system cells. In fact, sex hormones affect immune cell function and development directly also the capability of cells and tissues toward injury from autoimmune processes. Research in the early Forties indicated that women's ability to produce antibodies has increased. This increase of immune reactivity in females causes an efficient protection from contagion as a result female are less susceptible to viruses. However, females are prone to immune-pathogenic influences and hyperimmune reactions leading to autoimmune disorders.

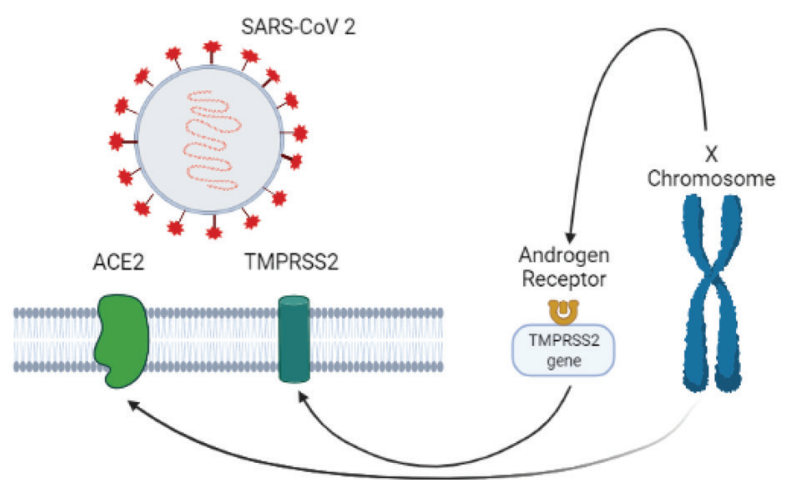

Figure 1. SARS-CoV-2 virus binds to ACE2 and TMPRSS2 receptors to enter host cells - androgen receptor activation increases TMPRSS2 expression
Besides, sex hormones could regulate the immune response through circadian rhythm. Interacting the sex hormones with ambient conditions such as smoking and infections caused different reactions in each sex. According to the evidence, sex hormones affect the microbial combination and the causing immune reaction through secondary metabolites connected to receptors like estrogen receptors and peroxisome proliferator-activated receptors. The immune reaction variations cause differences in phenotypes of the disease with autoimmunity which take place more frequently in females while cancers are more prevalent in males $(24,25)$.

The immunocompetence handicap hypothesis debate about a double efficacy of testosterone, the sex hormone in males has; regulating the expression and evolution of male sexually selected signals and also suppressing the immune system. So, just high-quality males can entirely introduce secondary sexual characteristics since they can endure suppressive effects caused by testosterone (26).

Sex hormones not only do they play an important role in fertility; however, they also have very important effects on the functioning of immune system components. Significantly, on the day of the admitting patients, the sex hormones were assessed to roll out possible unspecific impacts. A severe decrease of testosterone observed in male patients with COVID-19 could relate to changes in chemokine and cytokine amounts $(27,28)$.

In several surveys, the male elderly experienced a reduction in testosterone amount, which could associate with an increased pro-inflammatory status. Furthermore, it was revealed that treatment with testosterone caused a decrease in tumor necrosis factor $\alpha$ (TNF- $\alpha)$, interleukin$1 \beta$ (IL-1 $\beta$ ), and interleukin 6 (IL-6). Thus, Pozzilli and Lenzi (12) suggested testosterone might affect the progression of COVID-19 by the cytokine storm activation. In the controlling immune responses whether intrinsic or adaptive, the androgen receptor is involved. For example, in the neutrophil and macrophage turnover, associated with COVID-19 (29). 
Blood platelets-sex hormones interaction in COVID-19 patients

Past studies have stated that platelets have an important role in the fight against pathogens such as viruses, in addition to their hemostatic function. Platelets interact with viral pathogens via receptors. The interaction of platelets with viral pathogens results in activated platelets. Platelet activation causes the secretion of several molecules that fight viruses, including platelet microbicidal peptides and kinocidins. Furthermore, platelet activation develops an antiviral effect through several mechanisms such as the release of reactive oxygen species, phagocytosis of the viral pathogen, and interacting with and activating other immune cells.

Recent studies show that platelets can affect sex variations in vascular thromboses and that sex hormones can modify platelet functions. These results introduce a controlled potential of megakaryocytes to react with testosterone and consider an important mechanism by which sex hormones can cause thrombotic disorders and sex differences in platelet function.

In vitro testosterone seems to elevate platelet aggregation and estradiol inhibits aggregation of platelets from men $(30,31)$.

COVID-19 is a systemic contagious illness and has significant effects on the hemostasis and hematopoietic system. It can be suggested lymphopenia is one main laboratory recognition, with prognostic capability. Peak platelet/lymphocyte ratio and neutrophil/lymphocyte ratio can also be valuable in terms of prognostic to diagnose the illness in intense cases. During the period of the disease, linear measurement of inflammatory indexes and lymphocyte counts, such as IL-6, lactate dehydrogenase, and C-reactive protein could be useful in recognizing cases with stuffy prognosis and immediate intervention for early improvement. Moreover, among hospitalized COVID-19 patients blood hypercoagulability is very prevalent. In other coagulation disorders like partial thromboplastin time prolongation and prothrombin time, products of the fibrin degradation enhance, with serious thrombocytopenia cause life-threatening disseminated intravascular coagulation which require critical attention and immediate actions. Accordingly, the need for insuring donating blood throughout the pandemic is also distinguished (32).

During the course of infection with different pathogens, platelets accomplish basic immune functions. Additionally, in the alveolar capillaries platelets has an important role in the preservation of vascular homeostasis and endothelial integrity. Shedding of epithelial cells increases when the infection progresses. Infected endothelium, especially in the small vessels, where blood flow is lower than in the large arteries, may create thrombosis (7). Therefore, several mechanisms can be contributing to thrombosis at this stage of COVID-19 (33,34).

The low-platelet count is correlated with the enhanced danger of advanced illness and mortality in COVID-19 patients and thus should serve as clinical evidence of worsening disease throughout hospitalization.

Among COVID-19 patients, thrombotic complications are prevalent and are associated with failure in body organs and death. In severe cases of COVID-19 patients experience hemostatic disorders that emulate disseminated intravascular coagulopathy correlated with sepsis with the main variation being elevated danger of thrombosis more than bloodshed.

In patients with COVID-19, platelets accumulated rapidly and displayed enhanced spreading on collagen and fibrinogen. An increase in platelet activation and accumulation can partly be caused by enhanced mitogenactivated protein kinase (MAPK) pathway activation and the production of thromboxane (35-38).

\section{Discussion}

Coronavirus is the name of a great viruses family, which create several diseases from the common cold to severe pneumonia, such as SARS (39) and MERS (40). The SARS-CoV-2 was initially identified by the Chinese Center for Disease Control and Prevention (CDC) in Wuhan (41). Scholars recently have introduced each of the clinical $(44,45)$ and epidemiological $(42,43)$ properties of COVID-19 patients. Nevertheless, limited information has been revealed about the prognostic factors of COVID-19. In the countless cases of COVID-19, in the confirmation of past results $(46,47)$, old people ( $\geq 65$ years old) were more presumably to get the drastic type of COVID-19. Based on the clinical classification of severity, men are more susceptible to severe forms of the disease than women.

In addition, expressing the ACE2 could bring an important effect on the sex variation observed in COVID-19 implications. It has been confirmed by numerous researches that ACE2 is a co-receptor for the entrance of the SARS-CoV-2 virus into the cells of the human. This issue is important for virus pathogenesis (48). Several prior studies have demonstrated that the expressions of ACE2 occurred more in Asian males (49), which probably led to the results of this investigation. A higher sACE2 (men > women) in patients may bring a higher possibility to get severe COVID-19.

Other illustrations to why men were contributed to severe consequences compared to women in reaction to COVID-19 disease might include variations in immunologic response and the deficiency of estrogen protective impact observed in females; a discernment concluded from a study on MERS and SARS (50).

Since sex hormones modify immune function they sound to be the first candidates. The presence of the receptors of estrogen and testosterone on different immune organs and immune cells suggests that sex hormones can directly affect the immune system. Besides, the function of the immune system changes by removing gonads, the main source of sex hormones (40-50). 
While sex hormones were initially introduced to influence platelet function more than 25 years ago, the exact mechanisms of their operation have not yet been identified. It seems that in vitro testosterone elevates platelet accumulation and estradiol decreases the aggregation of platelets from men $(4,6)$.

\section{Conclusion}

The results of the study on patients with COVID-19 have demonstrated that male ones have more danger of developing the acute type of the disease than female ones. Furthermore, the mortality rate is more in male infected people compared to female ones. So, gender is an important variable that should be addressed more when treating patients. By surveying the studies around the gender variation in COVID-19 disease, it was found that some factors related to sex can affect the diagnosis of the patients' implications. The present study emphasized the impacts of testosterone on levels of ACE2 and variable amounts of ACE2 in males and females, and that locating the gene of ACE2 on the X-chromosome must not be neglected. Moreover, influencing gender on platelet functions, immune reactions, and datum existing about the immune system and sex variation in patients with COVID-19 have been illustrated. Anyway, the limited pieces of evidence in this field indicate that a lot of further studies are required.

\section{Authors' contribution}

NT and FRT participated in analysis and manuscript writing. HRS was responsible for data collection. All authors participated in preparing the final draft of the manuscript, revised the manuscript and critically evaluated the intellectual contents. All authors have read and approved the content of the manuscript and confirmed the accuracy or integrity of any part of the work.

\section{Conflicts of interest}

The authors declare that they have no competing interests.

\section{Ethical issues}

Ethical issues (including plagiarism, data fabrication and double publication) were completely observed by the authors.

\section{Funding/Support}

None.

\section{References}

1. Al-Lami RA, Urban RJ, Volpi E, Algburi AMA, Baillargeon J. Sex hormones and novel corona virus infectious disease (COVID-19). Mayo Clin Proc. 2020;95:1710-4. doi: 10.1016/j. mayocp.2020.05.013.

2. Habas K, Nganwuchu C, Shahzad F, Gopalan R, Haque M, Rahman S, et al. Resolution of coronavirus disease 2019 (COVID-19). Expert Rev Anti Infect Ther. 2020;18:1201-11. doi: 10.1080/14787210.2020.1797487.

3. Chakravarty D, Nair SS, Hammouda N, Ratnani P, Gharib Y, Wagaskar $\mathrm{V}$, et al. Sex differences in SARS-CoV-2 infection rates and the potential link to prostate cancer. Commun Biol. 2020;3:374. doi: 10.1038/s42003-020-1088-9.

4. Conti P, Younes A. Coronavirus COV-19/SARS-CoV-2 affects women less than men: clinical response to viral infection. J Biol Regul Homeost Agents. 2020;34:339-43. doi: 10.23812/
Editorial-Conti-3.

5. Hess DC, Eldahshan W, Rutkowski E. COVID-19-related stroke. Transl Stroke Res. 2020;11:322-325. doi: 10.1007/ s12975-020-00818-9.

6. Mishra JS, Hankins GD, Kumar S. Testosterone downregulates angiotensin II type-2 receptor via androgen receptor-mediated ERK1/2 MAP kinase pathway in rat aorta. J Renin Angiotensin Aldosterone Syst. 2016;17:1470320316674875. doi: 10.1177/1470320316674875.

7. Dalpiaz PL, Lamas AZ, Caliman IF, Ribeiro RF Jr, Abreu $\mathrm{GR}$, Moyses MR, et al. Sex hormones promote opposite effects on ACE and ACE2 activity, hypertrophy and cardiac contractility in spontaneously hypertensive rats. PLoS One. 2015;10:e0127515. doi: 10.1371/journal.pone.0127515.

8. Boese AC, Kim SC, Yin KJ, Lee JP, Hamblin MH. Sex differences in vascular physiology and pathophysiology: estrogen and androgen signaling in health and disease. Am J Physiol Heart Circ Physiol. 2017;313:H524-45. doi: 10.1152/ ajpheart.00217.2016.

9. Hoffmann $M$, Kleine-Weber $H$, Schroeder $S$, Krüger $N$, Herrler T, Erichsen S, et al. SARS-CoV-2 Cell Entry Depends on ACE2 and TMPRSS2 and Is Blocked by a Clinically Proven Protease Inhibitor. Cell. 2020;181:271-280.e8. doi: 10.1016/j. cell.2020.02.052.

10. Bhowmick NA, Oft J, Dorff T, Pal S, Agarwal N, Figlin RA, et al. COVID-19 and androgen-targeted therapy for prostate cancer patients. Endocr Relat Cancer. 2020;27:R281-92. doi: 10.1530/ERC-20-0165.

11. Heurich A, Hofmann-Winkler $H$, Gierer $S$, Liepold $T$, Jahn $O$, Pöhlmann S. TMPRSS2 and ADAM17 cleave ACE2 differentially and only proteolysis by TMPRSS2 augments entry driven by the severe acute respiratory syndrome coronavirus spike protein. J Virol. 2014;88:1293-307. doi: 10.1128/JVI.02202-13.

12. Pozzilli P, Lenzi A. Commentary: Testosterone, a key hormone in the context of COVID-19 pandemic. Metabolism. 2020;108:154252. doi: 10.1016/j.metabol.2020.154252.

13. Okwan-Duodu D, Lim EC, You S, Engman DM. TMPRSS2 activity may mediate sex differences in COVID-19 severity. Signal Transduct Target Ther. 2021;6:100. doi: 10.1038/ s41392-021-00513-7.

14. Lucas JM, Heinlein C, Kim T, Hernandez SA, Malik MS, True LD, et al. The androgen-regulated protease TMPRSS2 activates a proteolytic cascade involving components of the tumor microenvironment and promotes prostate cancer metastasis. Cancer Discov. 2014;4:1310-25. doi: 10.1158/2159-8290. CD-13-1010.

15. Azouz NP, Klingler AM, Callahan V, Akhrymuk IV, Elez K, Raich L, Henry BM, et al. Alpha 1 antitrypsin is an Inhibitor of the SARS-CoV-2-priming protease TMPRSS2. Pathog Immun. 2021;6:55-74. doi: 10.20411/pai.v6i1.408.

16. Stopsack KH, Mucci LA, Antonarakis ES, Nelson PS, Kantoff PW. TMPRSS2 and COVID-19: serendipity or opportunity for intervention? Cancer Discov. 2020;10:779-82. doi: 10.1158/2159-8290.CD-20-0451.

17. Wu R, Wang L, Kuo HD, Shannar A, Peter R, Chou PJ, et al. An update on current therapeutic drugs treating COVID-19. Curr Pharmacol Rep. 2020;11:1-15. doi: 10.1007/s40495020-00216-7.

18. Maggio R, Corsini GU. Repurposing the mucolytic cough suppressant and TMPRSS2 protease inhibitor bromhexine for the prevention and management of SARS-CoV-2 infection. Pharmacol Res. 2020;157:104837. doi: 10.1016/j. phrs.2020.104837.

19. McKee DL, Sternberg A, Stange U, Laufer S, Naujokat C. Candidate drugs against SARS-CoV-2 and COVID-19. Pharmacol Res. 2020;157:104859. doi: 10.1016/j. phrs.2020.104859.

20. Baratchian M, McManus JM, Berk MP, Nakamura F, Mukhopadhyay S, Xu W, et al. Androgen regulation of 
pulmonary AR, TMPRSS2 and ACE2 with implications for sex-discordant COVID-19 outcomes. Sci Rep. 2021 May 27;11:11130. doi: 10.1038/s41598-021-90491-1.

21. Stopsack KH, Mucci LA, Antonarakis ES, Nelson PS, Kantoff PW. TMPRSS2 and COVID-19: serendipity or opportunity for intervention? Cancer Discov. 2020;10:779-82. doi: 10.1158/2159-8290.CD-20-0451.

22. Habtemariam S, Nabavi SF, Ghavami S, Cismaru CA, Berindan-Neagoe I, Nabavi SM. Possible use of the mucolytic drug, bromhexine hydrochloride, as a prophylactic agent against SARS-CoV-2 infection based on its action on the Transmembrane Serine Protease 2. Pharmacol Res. 2020;157:104853. doi: 10.1016/j.phrs.2020.104853.

23. Dhama K, Khan S, Tiwari R, Sircar S, Bhat S, Malik YS, et al. Coronavirus disease 2019-COVID-19. Clin Microbiol Rev. 2020;33:e00028-20. doi: 10.1128/CMR.00028-20.

24. Walecki M, Eisel F, Klug J, Baal N, Paradowska-Dogan A, Wahle E, et al. Androgen receptor modulates Foxp3 expression in CD4+CD25+Foxp3+ regulatory T-cells. Mol Biol Cell. 2015;26:2845-57. doi: 10.1091/mbc.E14-08-1323.

25. Liva SM, Voskuhl RR. Testosterone acts directly on CD4+ T lymphocytes to increase IL-10 production. J Immunol. 2001;167:2060-7. doi: 10.4049/jimmunol.167.4.2060.

26. Roberts ML, Buchanan KL, Evans MR, Marin RH, Satterlee DG. The effects of testosterone on immune function in quail selected for divergent plasma corticosterone response. J Exp Biol. 2009;212:3125-31. doi: 10.1242/jeb.030726.

27. Nowak J, Pawłowski B, Borkowska B, Augustyniak D, DrulisKawa Z. No evidence for the immunocompetence handicap hypothesis in male humans. Sci Rep. 2018;8:7392. doi: 10.1038/s41598-018-25694-0.

28. Di Stadio A, Ricci G, Greco A, de Vincentiis M, Ralli M. Mortality rate and gender differences in COVID-19 patients dying in Italy: A comparison with other countries. Eur Rev Med Pharmacol Sci. 2020;24:4066-7. doi: 10.26355/ eurrev_202004_20980.

29. Aggarwal S, Gollapudi S, Gupta S. Increased TNF-alphainduced apoptosis in lymphocytes from aged humans: changes in TNF-alpha receptor expression and activation of caspases. J Immunol. 1999;162:2154-61.

30. Wang D, Hu B, Hu C, Zhu F, Liu X, Zhang J, Wang B, et al. Clinical Characteristics of 138 hospitalized patients with 2019 novel coronavirus-infected pneumonia in Wuhan, China. JAMA. 2020;323:1061-9. doi: 10.1001/jama.2020.1585.

31. Terpos E, Ntanasis-Stathopoulos I, Elalamy I, Kastritis E, Sergentanis TN, Politou M, et al. Hematological findings and complications of COVID-19. Am J Hematol. 2020;95:834847. doi: 10.1002/ajh.25829.

32. Li T, Lu H, Zhang W. Clinical observation and management of COVID-19 patients. Emerg Microbes Infect. 2020;9:687-90. doi: 10.1080/22221751.2020.1741327.

33. Singh S, Sharma A, Arora SK. High producer haplotype (CAG) of $-863 \mathrm{C} / \mathrm{A},-308 \mathrm{G} / \mathrm{A}$ and $-238 \mathrm{G} / \mathrm{A}$ polymorphisms in the promoter region of TNF- $\alpha$ gene associate with enhanced apoptosis of lymphocytes in HIV-1 subtype C infected individuals from North India. PLoS One. 2014;9:e98020.

34. Liao YC, Liang WG, Chen FW, Hsu JH, Yang JJ, Chang MS. IL-19 induces production of IL- 6 and TNF-alpha and results in cell apoptosis through TNF-alpha. J Immunol. 2002;169:428897. doi: 10.4049/jimmunol.169.8.4288.

35. Lippi G, Plebani M, Henry BM. Thrombocytopenia is associated with severe coronavirus disease 2019 (COVID-19) infections: A meta-analysis. Clin Chim Acta. 2020;506:145148. doi: 10.1016/j.cca.2020.03.022.

36. Zaid Y, Puhm F, Allaeys I, Naya A, Oudghiri M, Khalki L, et al. Platelets Can Associate with SARS-Cov-2 RNA and Are Hyperactivated in COVID-19. Circ Res. 2020;127:1404-18. doi: 10.1161/CIRCRESAHA.120.317703.

37. Koupenova M. Potential role of platelets in COVID-19: Implications for thrombosis. Res Pract Thromb Haemost. 2020:4:737-740. doi: 10.1002/rth2.12397.

38. Manne BK, Denorme F, Middleton EA, Portier I, Rowley JW, Stubben $\mathrm{C}$, et al. Platelet gene expression and function in patients with COVID-19. Blood. 2020;136:1317-29. doi: 10.1182/blood.2020007214.

39. Drosten C, Günther S, Preiser W, van der Werf S, Brodt $\mathrm{HR}$, Becker $\mathrm{S}$, et al. Identification of a novel coronavirus in patients with severe acute respiratory syndrome. $\mathrm{N}$ Engl J Med. 2003;348:1967-76. doi: 10.1056/NEJMoa030747.

40. Zaki AM, van Boheemen S, Bestebroer TM, Osterhaus AD, Fouchier RA. Isolation of a novel coronavirus from a man with pneumonia in Saudi Arabia. N Engl J Med. 2012;367:1814-20. doi: 10.1056/NEJMoa1211721.

41. Zhu N, Zhang D, Wang W, Li X, Yang B, Song J, et al. A Novel Coronavirus from Patients with Pneumonia in China, 2019. N Engl I Med. 2020;382:727-33. doi: 10.1056/NEJMoa2001017.

42. Li Q, Guan X, Wu P, Wang X, Zhou L, Tong Y, et al. Early transmission dynamics in Wuhan, China, of novel coronavirusinfected pneumonia. N Engl J Med. 2020;382:1199-207. doi: 10.1056/NEJMoa2001316.

43. Chan JF, Yuan S, Kok KH, To KK, Chu H, Yang J, et al. A familial cluster of pneumonia associated with the 2019 novel coronavirus indicating person-to-person transmission: a study of a family cluster. Lancet. 2020;395:514-23. doi: 10.1016/ S0140-6736(20)30154-9.

44. Huang C, Wang Y, Li X, Ren L, Zhao J, Hu Y, et al. Clinical features of patients infected with 2019 novel coronavirus in Wuhan, China. Lancet. 2020;395:497-506. doi: 10.1016/ S0140-6736(20)30183-5.

45. Chen N, Zhou M, Dong X, Qu J, Gong F, Han Y. Epidemiological and clinical characteristics of 99 cases of 2019 novel coronavirus pneumonia in Wuhan, China: a descriptive study. Lancet. 2020;395:507-13. doi: 10.1016/ S0140-6736(20)30211-7.

46. Zhang JJ, Dong X, Cao YY, Yuan YD, Yang YB, Yan YQ, et al. Clinical characteristics of 140 patients infected with SARSCoV-2 in Wuhan, China. Allergy. 2020;75:1730-41. doi: 10.1111/all.14238.

47. Wang D, Hu B, Hu C, Zhu F, Liu X, Zhang J, et al. Clinical characteristics of 138 hospitalized patients with 2019 novel coronavirus-infected pneumonia in Wuhan, China. JAMA. 2020;323:1061-9. doi: 10.1001/jama.2020.

48. Zhou P, Yang XL, Wang XG, Hu B, Zhang L, Zhang W, et al. A pneumonia outbreak associated with a new coronavirus of probable bat origin. Nature. 2020;579:270-3. doi: 10.1038/ s41586-020-2012-7.

49. Zhao Y, Zhao Z, Wang Y, Zhou Y, Ma Y, Zuo W. Single-cell RNA expression profiling of ACE2, the putative receptor of Wuhan 2019-nCov. BioRxiv. 2020. doi: 10.1101/2020.01.26.919985.

50. Channappanavar R, Fett C, Mack M, Ten Eyck PP, Meyerholz DK, Perlman S. Sex-Based Differences in Susceptibility to Severe Acute Respiratory Syndrome Coronavirus Infection. J Immunol. 2017;198:4046-53. doi: 10.4049/jimmunol.1601896. 